\title{
An Investigation of Public Art and its Role in Increasing Urban Quality: The Case of Arayampathy Batticaloa, Sri Lanka.
}

\author{
Arthy Yogalingam \\ Department of Architecture, \\ University of Moratuwa, Sri Lanka \\ Email: arthy156@gmail.com
}

\begin{abstract}
In this modern world, urban sculpture is considered as a cultural necessity in contemporary urban planning. Urban sculpture can reaffirm or reveal a sense of place in a symbolic and visually stimulating way of evoking some aspect of social, natural, cultural, physical, political, economic or historical context of the site and its locale. Typically, public artists produce site-specific sculptures and prominent installations that add character and distinction to a development and the surrounding neighborhood. After studying the city planning critiques viewpoints about public art's definition, nature and impact on city, this study evaluates the role of urban sculptures as a type of public art in enhancing public place quality in the case study of Arayampathy town, Batticaloa, Sri Lanka.
\end{abstract}

The aim of this research is to explore how urban sculptures play a significant role to enhance the urban quality and urban character. This research was conducted through observations, photographic surveys, activity mapping, cognitive mapping analysis, interviews and discussions with those who live in the selected case study area. What resulted was that through having some possible qualities and public art features, city sculptures Arayampathy have the ability to improve the qualities like legibility, sense of place, and pleasure besides developing local people's social interaction and local cultural identity.

Keywords: sculpture, sense of place, public art, cultural identity.

\section{Introduction}

In recent years, the role of public art in improving the quality of public spaces has been taken into consideration. Less obvious, but equally important, is that public art occupies space that is not up for sale and puts forward images and stories that are not trying to sell anything. Whether images projected on television or movie screens, signs and billboards, or glossy magazine spreads, people are being enticed to passively consume. The media have superseded the landscape as public space. Urban sculpture, if it is effective, actively engages the viewer. This engagement, physical, intellectual, or emotional creates reciprocal relationships, rather than a dehumanizing sales pitch. 
The flawed use of this art not only doesn't take our cities toward visual and social order, but in some cases also turns to be an additional factor to increase visual turmoil. While based on definition, public art belongs to the cities, is created in the cities, originates from the existence of cities, and its future is the future of the cities (Armajani, 1992). The proper use of this kind of art can be very effective in improving urban public space quality.

We may ask what is the relationship between urban sculpture and urban character? Communication is one thing, but there are others. The story telling and symbol-making components of urban sculpture communicating an urban vision is what matters, or ought to matter, and in particular, an urban area's social and personal relationships. Public art as a modern day myth and myths represents the urban sculpture of the urban area. "Urban sculpture itself epitomizes the myths of self interpretations of the lives in relation to the past world". They are narrations by which society is unified. Myths of the urban sculptures are essential to the process of keeping souls alive and bringing new meaning to the urban area (Sir Herbert, 1968).

\section{Literature Review}

Sculpture is considered not only as an urban decoration but also as a certain stipulation in improving visual quality of the urban environment. The term, urban sculpture of the city is applied to any kind of sculpture which is formed based on the needs and spatial structure of the environment while following its characteristics, and whose addition to the city environment is generally done with the purpose of completion, improving or adjusting urban space (Dufrenne ,1973). In addition, other cultural and artistic triumphs, sculpture holds a special position in representing imaginative outlook, emotions and goals in the history. In fact, city sculptures constitute a major part of public art collection (Greenberg, 1961).

City sculptures not only help enrich visual quality of our city and our social life space, but also are reliable as symbols and signs of our collective identity and culture; hence, viewers should have a fresh and more serious outlook toward them (Raphael, 1968). These public art works, as elements of the urban environment, should according to regulations and overall city needs and requirements and urban visual qualities, be chosen and installed so that in addition to not add to crowded urban environment and not reduce the effectiveness and impression of the sculpture, they can play their role in helping improve urban space qualities (Michalski, 1998).

\subsection{The effects of public art in improving urban quality}

The most important mission of urban designing is to improve Man's quality of life. But to achieve this, designers need special tools. Kevin Lynch says: if urban design is meant to be useful, it should be able to by elevating the quality of the physical environment help improve the human life quality (Lynch, 1960).

Use of public art is a step toward increasing the environmental quality in urban spaces. Public art in the city makes recognizable and memorable signs in public spaces and forms and improves a special picture of the city. A work of art can represent itself in the form of something in an urban environment or, through its spatial quality, cause to increase visual emotional quality of urban environment and change city space to city place. (Moradi, 1386) 
Environmental sculpture can be effective as one of the basic foundations in environmental design to create novel urban space; a desirable space which has the ability to create intellectual belonging, innovative space, and finally, the contemporary Man's deserved space.

\subsection{Why urban sculpture is important?}

Imagine, a world devoid of public art: no Statue of Liberty, no Eiffel Tower, no Vietnam Veterans Memorial, and no Tribute in Light. No murals, memorials, or monuments. What would life be like without fireworks displays, puppet parades, sculpture parks, and visionary roadside folk art? These landmarks and special events enhance our experience of a place and our quality of life. They engender a sense of pride and community identity. They reach audiences outside museums, galleries, and theaters, and they add to the beauty of everyday life. They declare the worth of a place and a time in our shared culture.

Urban sculpture does many things, most of which can be divided into four areas. Urban Sculptures increasing urban quality through providing local identity and spiritual identity, space, form and function, meaning and semiotics in urban planning, meaning and value.

\subsection{Identity and Spiritual Identity}

Identity is one of the most controversial issues of the present age and everyone have a kind of identity concerns, but most discussions instead of realizing the issue and finding a feasible way to resolve it, just reflect this concern. Although this reflection in turn is essential, but if do not lead to practical solutions to deal with the problem, in practice, don't have any result except arouses anxiety and denial of confidence between them. In fact, the identity is a response to people (Sajjadi, 2002).

Emergence of identity crisis may be a predisposing factor for authentication attempts. The result of identity confirmation and authentication is the spiritual identity of measured space from the perspective of the person and community and its necessity is a situation which may provide a spiritual identity for a space. With the recognition of this condition, it is possible to direct a space where affected by identity crisis to the desired authentication and during changes, preserve the identity-full space from identity crisis. On the other hand, this should be considered that the identity gets its validity from recognizable being. Thus, the most important condition for spiritual identity is recognizable being. Meanwhile, the recognizable affairs are space, diagnostic criteria, mental image and the space's closeness to expectations (Ghasemi, 2004).

\subsection{Space, Form, Function}

Wherever the identity full space is discussed, in fact, place is the subject. The place is a portion of the space which in occupied by someone or something and its meaning is valuable. In other words, the place is where function and meaning of space interact. (Sattari, 2003). 


\subsection{Meaning and Semiotics in Urban Planning}

Public space becomes a territory to explore identity and reduce pressures of modern life in the shadow of historic landmarks (Verlag, 1997).

Urban planners can emphasize on steering and directing the changes to the meaningful environment, people and their environment and/or both of them. Designers must not ignore people that is extremely effective to understand and use the characteristics of their environments in a better way. A successful urban design requires satisfying of human behavior values. In fact, an urban designer should know what people know, what people celebrate, what people remember and what they remind which relate to the symbolic, cultural, historic and meaning aspects of urban spaces (Bahraini,2008).

Urban sculpture can act like symbols. Symbols usually predominate the surrounding area, with their effective size and shape. Thus, they can be used as a basis for orientation in all aspects. Specific characteristics of the sign, it is unique, which is exclusive and memorable in the minds of visitors. If the symbols have obvious form and conflict with their field or their position dominate around, it is easy to recognize (Lynch, 1960)

\subsection{Urban Sculpture: Identity, Meaning, Value}

Urban sculpture is among the important physical factors which urban designers can use them to help the human and social manifestation. These statues can be analyzed from several perspectives and context. The goal is the first point. This means that the purpose of designing and implementing an urban sculpture is to realize one of human values. Memories and flashbacks, or sign of a tradition, culture and faith is more important for a man or orientation to modern art. The public perception should be considered or art generalities and modernization. The identity and tradition should present values in the form of tradition or modernity?

The relevant location is the first thing which should be considered in applying statues in the city. Sculpture in the right place can be used as an element for the creation of beautiful or special meaning for citizens. Other features of urban sculpture are compatibility with the surrounding environment and closeness to cultural atmosphere, considering principles and fundamentals of the visual arts, understanding the relationship between space and volume and its close relationship with the installation place and location, emphases on national and cultural characteristics and paying attention to the aesthetics of the sculptor, valuing the arts and supporting the artists by municipal authorities and using the art of indigenous sculptors of any region, all are other requirements that must be emphasized. (Mazinani, 2007)

The sculptures' main function is deportation, identity or transmitting a message to the visitor. Urban sculpture has different visitors, in a way that illiterate people are looking at these volumes. Urban sculpturing is the common work of sculptors, urban designers, landscape designers and urban planners that are done with the support and guidance of urban managers. The aim of this cooperation beside of the functional considerations is to create more visual pleasure for observers. (Saidi, 2008) 


\section{The Research Methodology}

As graphically represented below, this research evolved and developed through an indepth research process which consisted of the stages of the preliminary study, study area selection and research study while gaining discipline, knowledge, training, practice in the process of investigation.

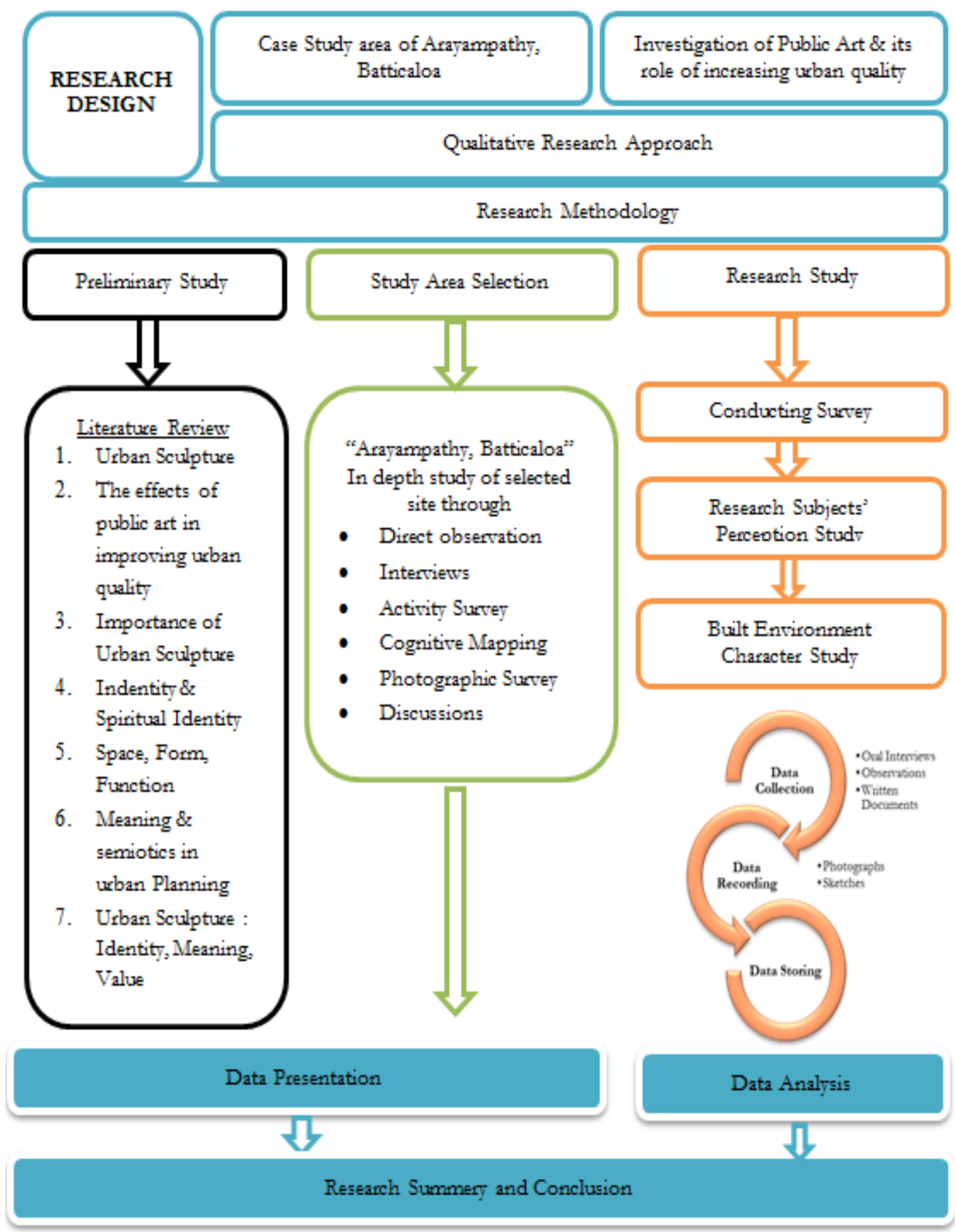




\section{Direct Observation}

Observe the Arayampathy area, surroundings and sculpture locations get the idea about the activity. Most importantly observe the sculpture's role in increasing the urban quality, sculpture's cultural values and formation of spaces. And observe how sculptures give meaning and legibility to the Arayampathy area.

\section{Unstructured Interview and Discussions}

Unstructured interviews and open discussions allow questions based on the interviewee's responses and proceeds like a friendly non-threatening conversation. Here mainly focus the people those who visit the Arayampathy area and get the idea from them whether they like the strip of the sculptures or not and what their expectations and ideas on urban spaces.

\section{Activity Survey}

Activity survey is an investigation about the characteristics of the sculptures and the surrounding area. According to this survey tried to observe the activity pattern and its functions also the interconnections between different spaces.

\section{Cognitive Mapping}

Let the people to visualize the Arayampathy area. People will draw the picture of the area how they capture the area in their mind. So, according to that able to identify the important spatial elements, especially focal points of nodes, paths, edges, districts and landmarks.

\section{Photographic Survey}

Photographic survey is focused on what really happen in the ground level, and also through photographic survey, observations have done with line of interview content to see whether the reality of designing works have done according to the people's aspirations and needs. Through an organized photographic survey in the case study area the human behavioral aspects and conflicting situations will be identified. And also the activities and symbolic features were recorded in photographs, sketches and maps.

\section{Case study area}

In Arayampathy, there are a few numbers of the public art works which are made based on the associated designing standards and conditions. There are many statues located in the middle of the road which represents the Tamil culture and identity, in addition to vivaciously narrating the history of Tamil King's Princes, poets, etc., Observation suggests has caused strong behaviors in the surrounding area because of being significant of the past happenings and occurrences. 
The significant landmarks of the historic events of Batticaloa, Arayampathy are preserved in this selected area and the predominant feature here is the 'urban sculptures'. It reflects the Tamil culture and the past history.

\section{Scope and limitation}

Public art is a very broad concept. With the time limit it is not possible to do research by considering the all aspects of public art and its role. So, mainly this research limits to investigate the public art and its role of increasing the urban quality. Therefore, this research will leads to do further researches related to the public art in future.

\section{Analysis and Findings}

The creation of the sculptures of the works has been carried out disregarding the other important elements such as the statue's conformity with the surrounding area, material durability, the relationship of material and the shape, performance quality, respecting audience's understanding and perception, attention to the novel perspectives in urban sculpture etc. That's why the essence of particular area's urban sculpture in its finest cases consists of some sculptures of Swami Vivekanander, King Ellalan, KalaiVanji, Ulaganachchiyar (Princess), SubramaniyaParathiyar, Thiruvalluvar and Swami Vipulananthar similar to their characters, having suspicion of their geniuses, dedication and sacrifice.

According to some open interviews made with a group of Arayampathy people, approximately all the local people of the area consistently acknowledged that all urban sculptures are one of the long-lasting and perhaps the only important public sculpture of the town. It is worth quoting that most of the aforementioned people interviewed dwelled in some areas other than the selected case study area of Batticaloa and this shows that the urban sculptures have reached beyond its neighborhood and plays its role in the area and city despite being located in a neighborhood with attractive and memorable. 
Vol. 2, Issue 2: July 2017

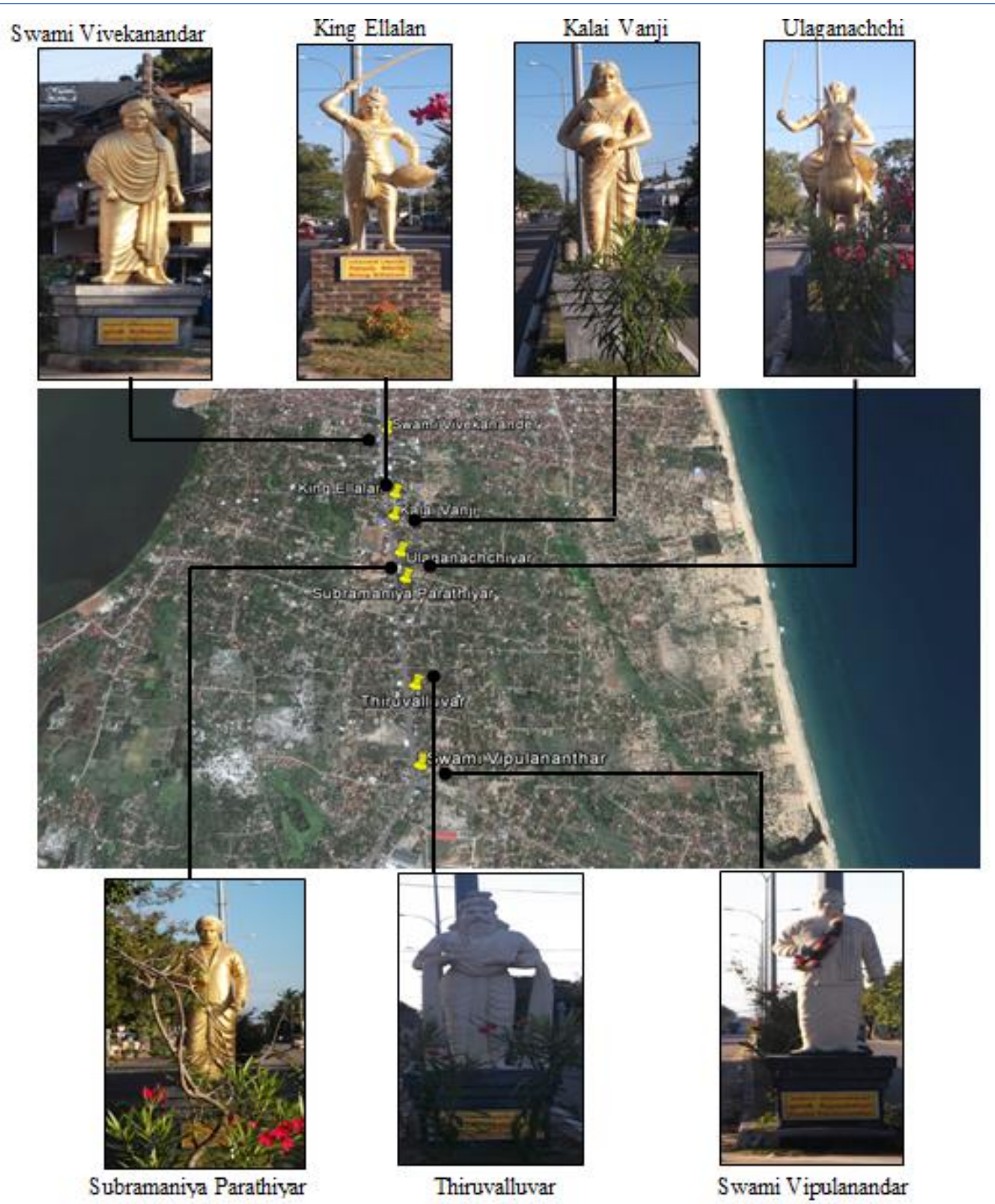

Fig 1: Essence of Arayampathy Area's Urban Sculptures

Source: Author

\subsection{Sense of Place}

Nearly $92 \%$ of the interviewees expressed their interest and sense of place to the sculptures and most of them stated the reason for that through words such as "being meaningful, significant of the happenings and social life and cultural background of the past in their minds", "getting people to know about the history of Tamils", "dynamism and liveliness of the work (its uniqueness in terms of its shape)", "presenting people from different walks of life with different Social characters", "the harmony of the work with the work position".

Also, regarding status, $81 \%$ of the interviewees whether were fascinated with the work or was different about it due to the sense of place in the past. They stated that they do have an 
impression of the work because it did rejuvenate the past experience concept in their minds and reminded them of a lot of thing and 19\% of the interviewees believed that all the statues were beautiful and praiseworthy on account of its distinction and originality.

About $67 \%$ declared that they had a lot of tendency to approach the sculptures and touch it personally, but they had done so because of some reasons such as the suitable position of the work, the limited space around it and also suitability of such behaviors in Tamil culture, and Tamil interest to sculpture is somewhat that $60 \%$ of the interviewees showed their enthusiasm for perceiving the work one more time while passing by the street despite the repeated observation of the work by them by the time.

By considering all the above-mentioned responses into account it can be said that out of local peoples' sense of attachment to the sculptures informative role in notifying them of their local and cultural identity and also the existence of Vivekanander, King Ellalan, KalaiVanji, Ulaganachchiyar (Princess), SubramaniyaParathiyar, Thiruvalluvar and Swami Vipulananthar as familiar elements in historical memory of people, the attachment of the people to the place has increased greatly and people's sense of place from the area has faded leading to the increased understanding of people with the area due to this connection. Therefore, the work has an educational role in addition to strengthening the sense of belonging to the area and creating the sense of vitality and identity in people besides making a sense of connection among them.

\subsection{Space, Form and Function}

Arayampathy is one of the ancient villages in the land of singing fish consists with rich traditions and cultures. Consider to the space; it locates around $6 \mathrm{~km}$ south of Batticaloa town on the Batticaloa - Kalmunai main road neighboring popular Kattankuddy town.

The current landmark of the village is the several "Statues" (bronzes) of great personalities including ancient kings, Queens and Community leaders, constructed in the middle of the road in a long line. Some people refer Arayampathy as 'village of statues' for this reason. There are several natural and man-made attractions one would find in this village. As mentioned above, there are seven bronze statues, Arayampathy Beach, Hindu Temples (47), Mosques (17) and Churches (11) of historical importance. The annual festivals of Sri KandasamyKovil, Kannaki Amman Kovil and Fatima Church are very popular events. Also Banks, Play Ground, School, Fuel Station, Public Market, Post Office, MannmunaiPradeshiya Saba, Private Campus, Archeology Department and many other places located along the two sides of the roads. Mostly these places are located close to the statues. Activity patterns were studied in order to grasp its complexity with regard of actors, location, their processes and the structure within which these activities are carried out along the road and its surroundings. Especially this location enhances a lot of activities and it has well connectivity as well. 


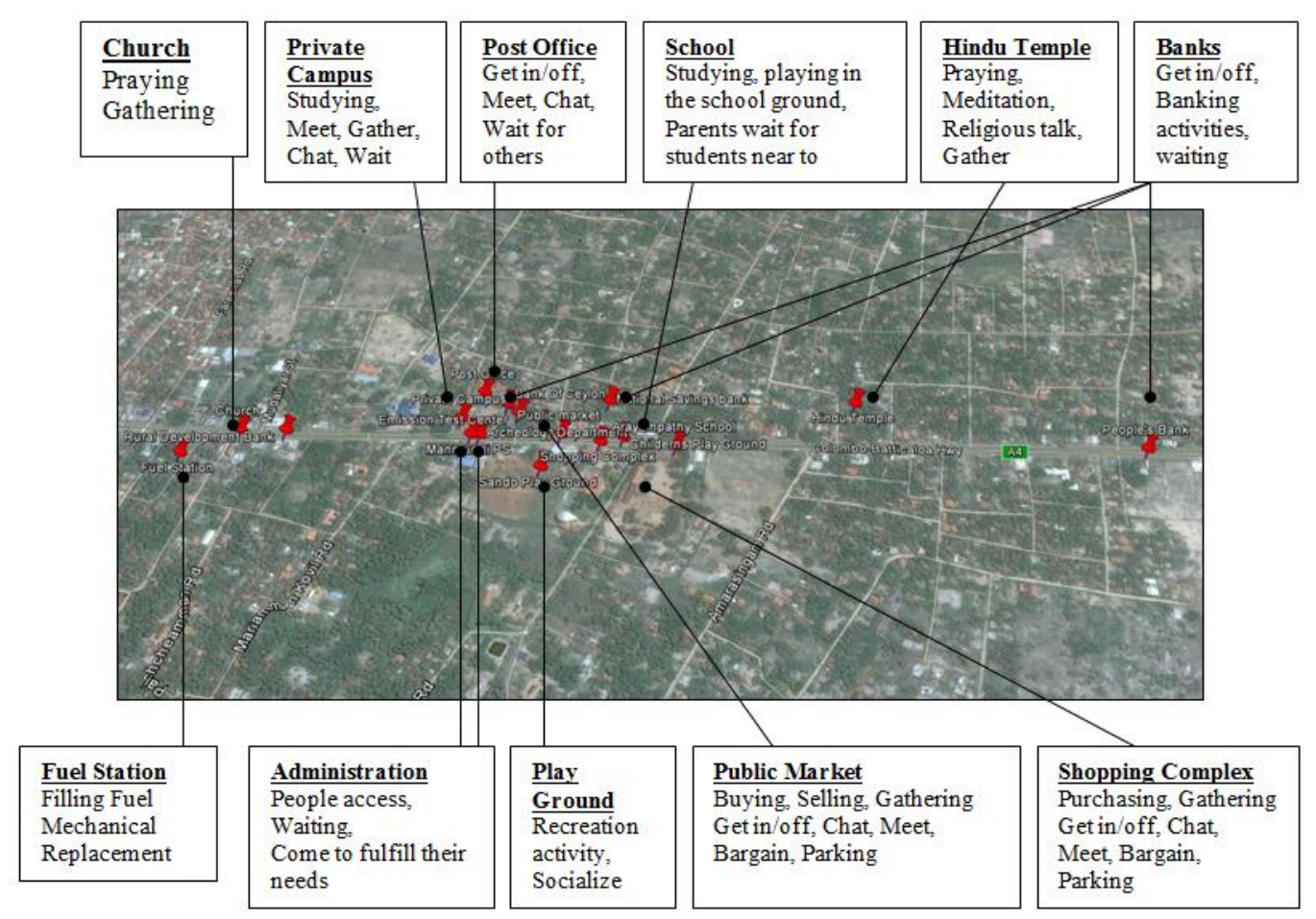

Fig 2: Activity Pattern of Street and its Surrounding of Urban Sculptures

Source: Author

\subsection{Cultural Identity}

The significant landmarks of the historic events are preserved in Arayampathy area and the predominant feature here is the 'Statues of Famous Persons'. They reflect the Tamil culture.

The result of identity confirmation and authentication of sculptures provides spiritual identity for a space. With the recognition of this condition, it is possible to direct this particular place for visitors. Also, these sculptures' mainly function as a deportation, identity or transmitting a message to the visitor. These urban sculptures attract different visitors, in a way that literate the people and they give own identity to the place. Not only has that, but also sculptures created more visual pleasure for observers.

\subsection{Legibility and Social Interaction}

Considering the statues, despite its harmony with the area, the connection between the local people and the work has been fully established due to some reasons such as wide-ranging understanding of the work recognitions to its position circumstances and also familiarity of content and theme comprehension of the work by a lot of people.

Approximately 65\% were dissatisfied with the current location of the Swami Vivekanandar statue (in the middle of traffic nod on the platform) and believed that the people have been deprived of fully understanding and observing and physically contacting with the work 
because of the sightseeing of the first sculpture difficulties to the work firstly due to its location in the vehicles' course and secondly its high position. These people generally stated that if the work were positioned with sidewalks or if there were more space for sitting or walking around the statue not only the work could communicate more effectively with the audience, it could also play a supportive role in forming the social interactions.

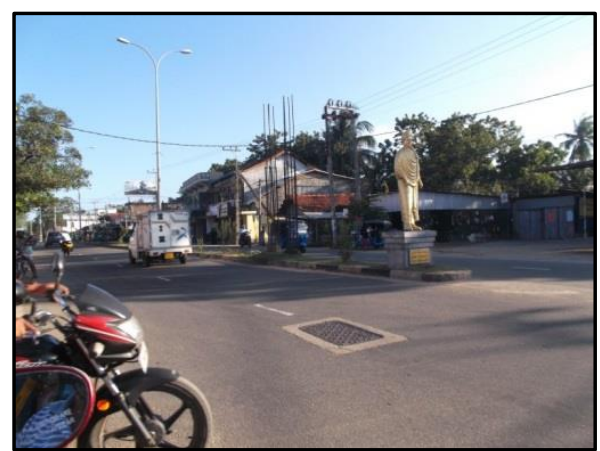

Fig 3: Swami Vivekanandar Statue locates in the middle of traffic nod Source: Author

Nearly $90 \%$ considered the statues as an iconic element in building their mental image of and used it as a mark in orienting. Just about all the people interviewed took the statues as a strong element as a mark for directing people compared to other constituting elements of the street such as the large roundabout and the administrative complex, schools, market and the commercial in the area. $50 \%$ of the interviewees viewed the statue as an iconic element in creating their mental image and the other $50 \%$ believed that the role of the statue in forming their mental image was very strong and memorable probably because of the figures' concentration in the area (street such as the large roundabout and the administrative complex, schools, market and the commercial) and the location of the statue on the course of street way which makes it easy to observe and understand the work.

Owing to the fact that all statues have a leading role in creating local people's mental images of the place, therefore they are helpful in the legibility of the area. The sculptures are also pragmatic in directing people as an iconic and understandable symbol and statues are in practical use of directing people, probably because of its sense and identity (name or title).

Conclusions can be drawn considering the discussions, first of the people's need and aspirations for the public places and having social interactions, and secondly, identifying the characteristics of public art which are liked by people and attract them and the most important ones among them is the novelty of the work along with the familiar components of history, culture and people's lifestyle. The overall work seemed to have a marvelous symbolic role in its best case scenario.

\section{Conclusion}

Due to the fact that the public art looks unique and distinct from a visual perspective, it takes a more symbolic role and manifests itself in city identity and legibility, When it is designed and created in reliability with its area and location specifications in addition to innovation, it can improve the town vitality, place attachment and security originated from understanding the familiar elements and can intensify social interactions through establishing a connection with citizens and associating the place with people's minds. 
Despite all these shortages and numerous problems, whether in conceptual areas and works contents or in administrative dimensions are also supervisory measures against public art and sculpture in Arayampathy area, this art to some extent could present an acceptable role in challenging local people's mind and associating cultural and identity-related concepts and contents with his minds, hence leading to his heightened sense of place to the city.

The urban sculpture recognized as the important contribution of public art to the quality of the public realm and to city building. Public art helps to make buildings, open spaces and neighborhoods attractive and memorable places where people want to visit, live, work and play. Urban planning looks forward to continuing success with public art on a citywide basis. And also urban landscape is the art of giving a visual integration and structure of buildings, streets and spaces that make up the city environment as a combination of artificial and natural spaces and this composition generally tries to inspire a certain sense of meaning and identity. In order to achieve this goal, a variety of techniques and methods may be used that one of the most important are the methods and tools of urban sculpture which the same urban statues, depending on the context, need, site and design planning can play a role in the representation of its meaning in different ways. This role can be held in the form of tradition, modernity, and realism, abstract, conceptual or a quite simple shape and form and play its role in establishing or changing the identity, culture and meaning. The results show that urban sculpture has the major visual and meaning impact to induce meanings and identity of a society and a city and by applying an accurate planned designing and implementing, it is possible to show respect for human and society values in a city through urban sculpture.

\section{References}

Armajani, Sivash (1992) Public Art, Tandis Magazine, issue 46

Bahraini, H. (2008) 'The process of urban design', University of Tehran Press, No. 4.

Dufrenne. M (1973) 'The Phenomenology of Aesthetic Experience'. Evanston: Northwestern University.

Ghasemi, M. (2004) 'Where we come from?',Rozaneh Publication, Tehran.

Greenberg, C. (1961) 'Art and Culture'. Boston: Beacon Press.

Lynch, K. (1960). The Image of the City. Cambridge, mass and London: The Massachussets Institute, Technology Press.

Mazinani, F. (2007) 'Urban sculptures, ugly, beautiful, undecided', Journal for Municipalities.

Michalski, S. (1998). 'Public Monuments: Art in Political Bondage, 1870-1997'. London: Reaktion Books.

Raphael, M. (1968). 'The Demands of Art'. Princeton: Princeton University.

SaidiRamezani, N. (2008) 'Sculptures bring art to the people', Tandis Journal, No. 2.

Sajjadi, R. (2002) 'Can art challenge architecture', urban spaces 88.

Sattari, A. 'National and cultural Identity', KabirPublication,Tehran.

Sir Herbert, R.(1968). 'The Art of Sculpture'. New York: Pantheon.

Verlag, G.H. (1997) 'Contemporary sculpture, projects in Munster', Edited by: Klaus Bubmann, Published by HatjeCantz Publishers. 